\title{
Materials Flow of Platinum Group Metals in Germany
}

\author{
Christian Hagelüken ${ }^{1}$, Matthias Buchert ${ }^{2}$, Peter Ryan ${ }^{3}$ \\ ${ }^{1}$ Umicore Precious Metals Refining, Hanau, Germany \\ ${ }^{2}$ Öko-Institut, Darmstadt, Germany \\ ${ }^{3}$ GFMS, London, United Kingdom
}

\begin{abstract}
Platinum Group Metals have become indispensable in modern industrial society and the demand for PGMs has greatly increased. An in-depth quantitative analysis of PGM applications, lifecycle structure, deficits and optimisation potential in Germany has been carried out by Umicore Precious Metals Refining and ÖkoInstitute. Besides detailed insights into one of the more opaque metal markets, the study elaborates fundamental differences between lifecycles of industrial applications and those in the consumer sector, which are relevant beyond PGMs also for other materials. While "closed loop" systems in the industrial sector inherently lead to high lifecycle recycling rates, the "open loop" consumer systems usually imply significant metal losses. Main deficits lay in insufficient collection rates of end-of-life products, global export streams of "consumer scrap" and inefficiencies in the early, "sub-industrial" steps of the recycling chain. The study also develops the aspect of "static" and "dynamic" recycling ratios, which has to be considered when lifecycle efficiencies in growing (or decreasing) application areas are evaluated.
\end{abstract}

\section{Keywords}

Platinum Group Metals, PGMs, Materials Flow Analysis, Recycling ratio, Automotive Catalysts

\section{INTRODUCTION}

Platinum group metals (PGMs) are used in substantially increasing quantities in many of today's key technologies (catalysis, electronics, fuel cells), the strong demand has driven PGM prices to considerable heights ${ }^{1}$ (Figures 1, 2). Primary production of these metals is concentrated in only a few countries of the world and partially is connected with considerable environmental impacts. Recycling of PGMs is ecological advantageous and essential for the sustainable use of PGMs. Efficient recycling technologies for PGM bearing materials have been established for many years and have been used successfully. However, the recycled PGM quantities are substantially below the original PGM input for the various applications. A reliable data base in this context was not in existence and flows as well as cycles of materials were not transparent.

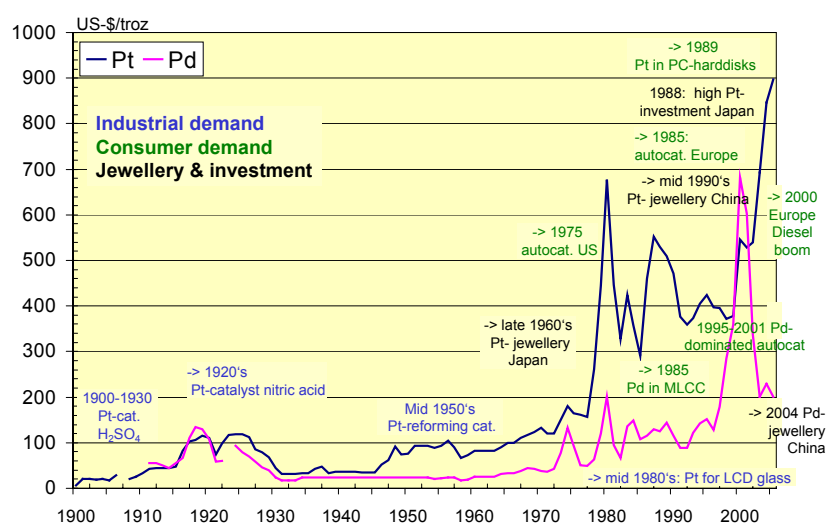

Figure 1: Long-term price development (annual averages) of platinum $(\mathrm{Pt}) \&$ palladium $(\mathrm{Pd})$ as well as milestones in their applications [6]

\footnotetext{
1 In early February 2006 platinum reached its all-time high of 1080 US-\$/troz, palladium went up again to $315 \$$ and rhodium to $3520 \$ /$ troz $(1000 \$ /$ troz $=32.15 \$ / g)$.
}

A research project, jointly conducted by Umicore, a leading refiner and fabricator of PGM products, and Germany's well reputed environmental research group, ÖkoInstitut, has now shed much more light on this subject. The joint research project obtained funding from Germany's Federal Ministry of Education \& Research. The analysis, which in its depth and breadth is unique, showed substantial differences between application fields, ranging from PGM lifecycle-efficiencies $>90 \%$ on the one side (e.g. chemical catalysis) to $<40 \%$ in areas like autocatalyst and electronics. Other key findings of the investigation are that Germany's inventory of PGMs in fabricated products stands at around 240 tonnes and that recycling from this covers just under half of the country's annual gross demand.

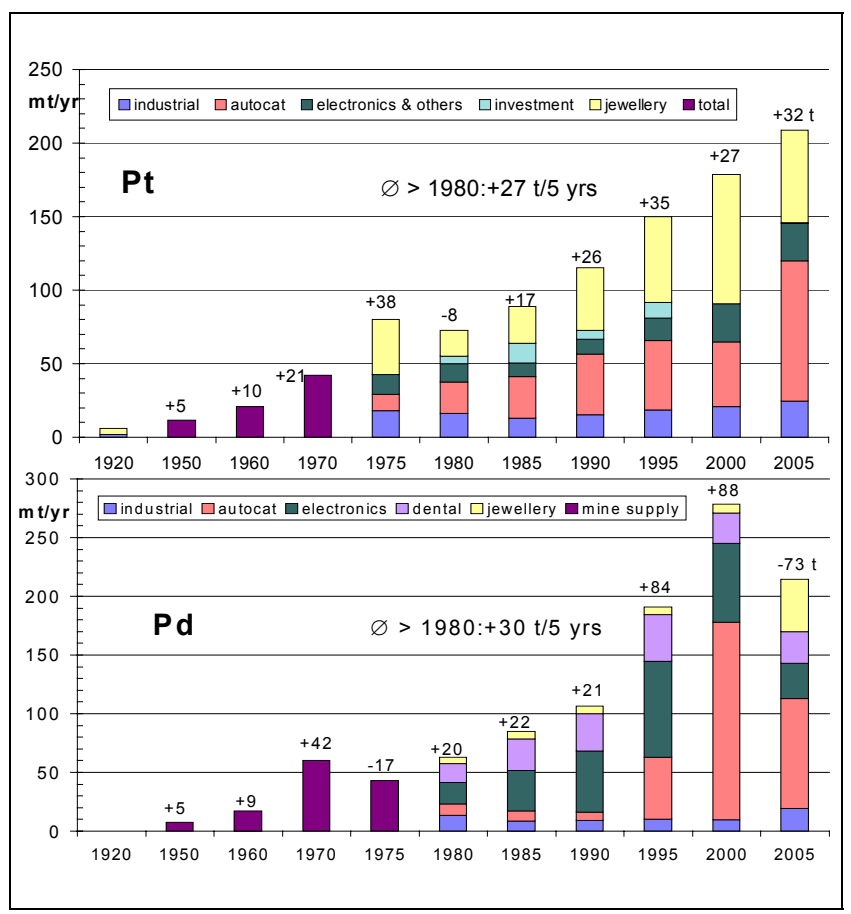

Figure 2: Long-term development in net-demand for platinum $(\mathrm{Pt})$ and palladium $(\mathrm{Pd})[6]$ 
The detailed statistics, analysis and conclusions were published in March 2005 in German language at GDMB Medienverlag [1]. In June 2005, an English language edition was published in conjunction with the London based precious metal analysts GFMS [2]. This includes a new section placing the German results in a global context and assessing whether any material changes had occurred since the early research was carried out. An executive summary was also added by GFMS.

The first section of the main report concerns estimates of the division of gross PGM demand by end-use sector and how much of each sector's requirements are met by recycled PGMs, generating a figure for the amount of PGMs 'irretrievably lost' each year. This research was then extended to assess the standing inventory of PGMs in each sector of end-use.

The second section covers possible future improvements to the amount of PGMs that can be recycled. A major reason behind the report's ministerial funding was a desire to raise recycling efficiencies. This desire was based on environmental concerns, as recovery from scrap tends to generate far less carbon dioxide and sulphur dioxide than mining of primary PGMs. To that end, the report recommends various measures to improve recovery rates.

As for its global relevance, Germany makes an excellent case study. Not only is it a major industrial consumer of PGMs, but the country is frequently 'ahead of the game' on environmental matters. Pointers can therefore be deduced as to what is already achievable with current technologies and practices and where recovery rates might be going as we move forward.

\section{METHODOLOGY AND SCOPE OF INVESTIGATION}

The focus and system limit is the Federal Republic of Germany. Global conditions for the materials flow of PGM have, however, been adequately considered. In many cases it is difficult to obtain quantitative data solely for Germany. Here, plausible quantity schedules were often compiled by means of top-down or bottom-up approaches. Important for assignment to the system under examination is the use of the PGM product, not the place of manufacture. In Germany, for instance, as a result of net imports more PGMs are used in electric and electronic applications than are used in the production in Germany of these items. On the other hand, as a major exporter the German automobile industry requires for the production of car catalysts more PGM than, in the end, is employed in vehicles in Germany.

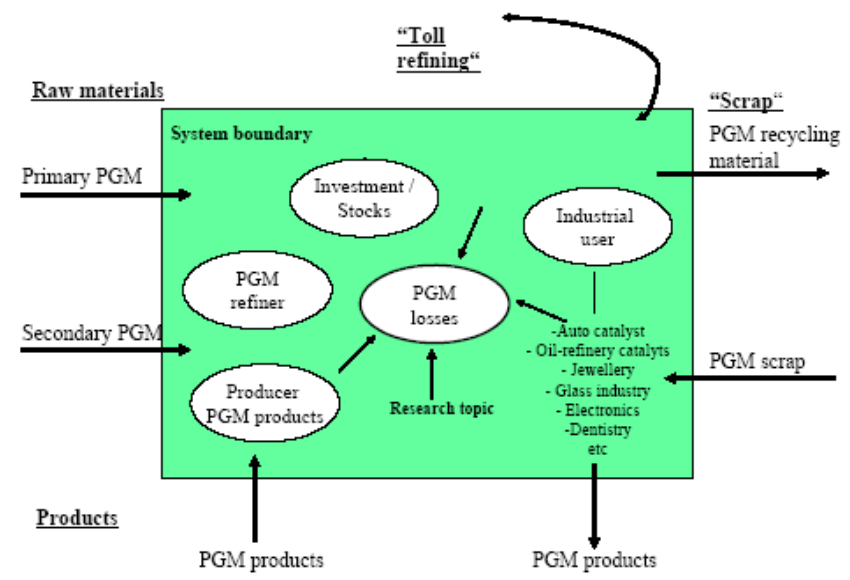

Figure 3: System limits and materials flow of PGM
The available database from public statistics is insufficient, and for Germany no data whatsoever is directly available. At the worldwide and European level, data are available from [4] [5], which, however, are restricted to mining supply and net demand within the main application segments. With the exception of automotive catalysts, no data are reported on gross demand, which ultimately manifests itself in PGM products. The bottom-up and topdown approaches to data, which are partly applied in the project to support the quantification of materials flow in Germany, are only possible on the basis of sound specialist knowledge of the relevant application segments as well as on a good knowledge of the systematics underlying the available statistics.

The bridge between net and gross demand is achieved through recycling, the interdependence is displayed in Figure 4. Here a lot of open questions exist:

- Which recycling potentials derive from the strong increase in PGM demand since the 1980s?

- What PGM materials are evading recycling and why do these losses occur?

- Why are actual recycling volumes often far behind the expected quantities?

- What kinds of lifecycle structures exist in the various PGM application fields?

- Why are recycling loops in some areas working highly efficiently but not in others?

- What are the deficiencies and what measures have to be taken to improve PGM supply from recycling?

- How will PGM demand evolve in the coming years and what contribution to PGM supply can we expect from recycling?

- What are the ecological consequences of these developments?

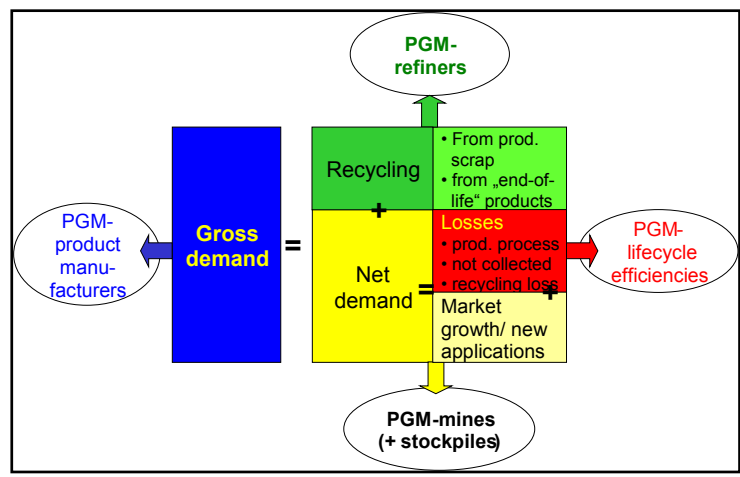

Figure 4: PGM demand interdependencies

Work on the project commenced in August 2001 and the final report was submitted to the ministry in August 2004. Areas of investigation have been all relevant application segments for PGMs:

- Automotive catalysts

- glass manufacturing

- chemical \& oil refining catalysts - dental applications

- electronics

- jewellery

- electroplating

- fuel cells \& others

The base year for data collection in Germany was 2001/02. A qualitative reference is made beyond the German situation to the worldwide PGM-industry and global statistics are updated with 2004 figures on demand/supply and PGM-price development. 


\section{THE MEASURING OF RECYCLING EFFICIENCY}

In the focus of the project were gross demand, recycling quantities and PGM-losses, since these factors are needed to calculate PGM lifecycle efficiency. The measurement of recycling efficiency is achieved by calculating recycling quotas for each PGM application. Recycling quotas (or ratios) have been calculated on two fundamentally different bases, „static" and „dynamic“ (Fig.5).

- "Static recycling ratios“ compare current levels of supply from recycling with current gross demand. In an application where PGM demand is rising, a product with a lifecycle of several years (e.g. an autocatalyst) will yield an inherently low ratio. Conversely, in an application where demand has been falling (e.g. $\mathrm{Pd}$ in electronics) the ratio will be inherently high.

- By contrast, „dynamic recycling ratios“ compare current levels of supply from recycling with the gross demand for that application at the time the recycled products were originally manufactured. This measure eliminates the distorting effects of rising or falling demand and represents the true measure of recycling efficiency within any given application.

In application fields with either short lifecycles (e.g. 1 year or less) or stable levels of demand, the static and dynamic recycling measurements will both yield similar results.

$$
\text { Static recycling ratio }=\quad \frac{\text { Recycling today* }}{\text { gross today }}
$$

dynamic recycling ratio $=$

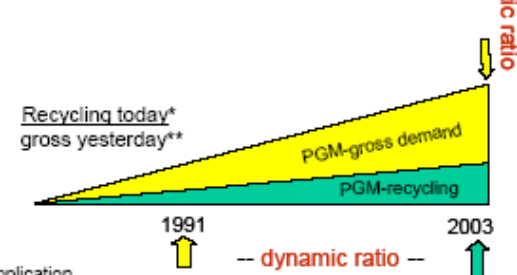

"today's" PGM-recycling from an application

gross PGM-demand for a segment

Figure 5: Recycling ratios in dynamic markets

\section{GERMAN PGM STATISTIC}

The following paragraph summarises the key statistical findings of the investigation in Germany. Much more background and details are given in [1] [2]

Figures 6 and 7 illustrate the quantitative results for Germany. The country's gross demand for PGMs in the base year (2001) was approximately 38 tonnes of which platinum comprised $58 \%$, palladium $37 \%$ and rhodium $5 \%$.

- Autocatalyst production accounted for $40 \%$ of total PGM gross demand, chemical industry catalysts $22 \%$ and glass industry products $13 \%$. Jewellery accounted for $9 \%$ of gross demand.

- $\quad 45 \%$ of gross demand was satisfied by recycled PGMs. New purchases represented only 55\%.

- Recycling of glass industry products and industrial catalysts accounted for over two-thirds of the total amount of PGMs recycled in Germany (Fig. 7).

- $\quad 85 \%$ of gross demand in the glass and industrial catalyst sectors was satisfied by recycling.

- PGMs recycled from scrapped autocatalysts represented only $12 \%$ of gross autocatalyst demand.

- In the base year 10 tonnes of PGMs escaped recycling and were considered "lost". $50 \%$ of this was platinum with palladium comprising $40 \%$ and rhodium $10 \%$. At current prices this represents a value of US-
\$280 million (Fig. 6). A breakdown of losses by sector is given in Figure 7 .
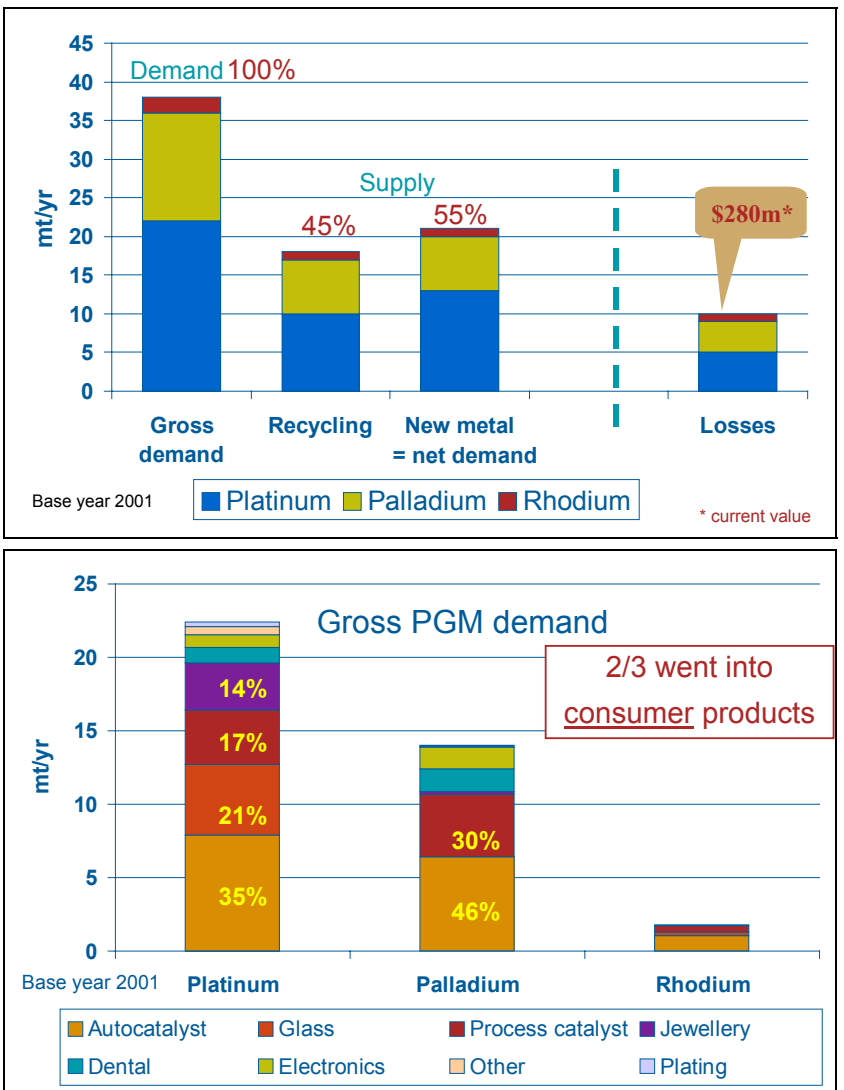

Figure 6: PGM demand-supply balance for Germany and gross demand by sectors (base year 2001)

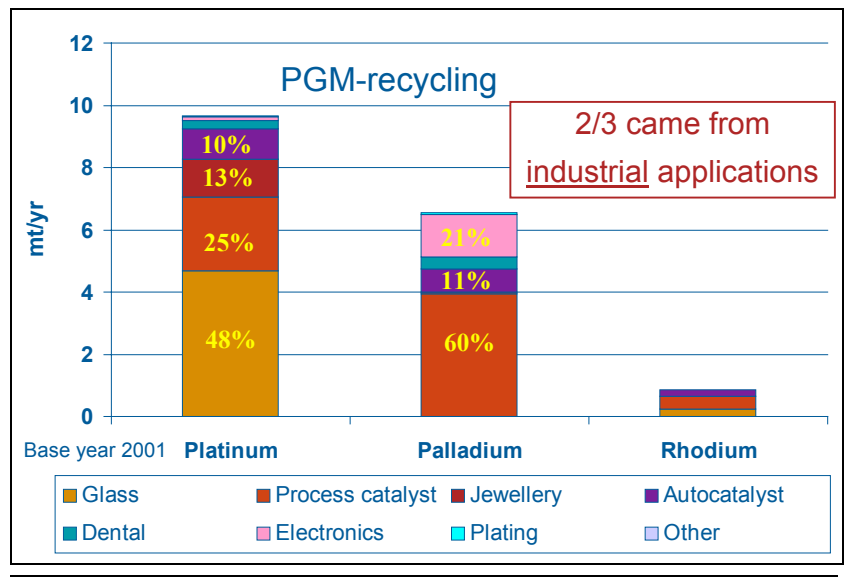

Total PGM losses 2001: 10.3 tonnes

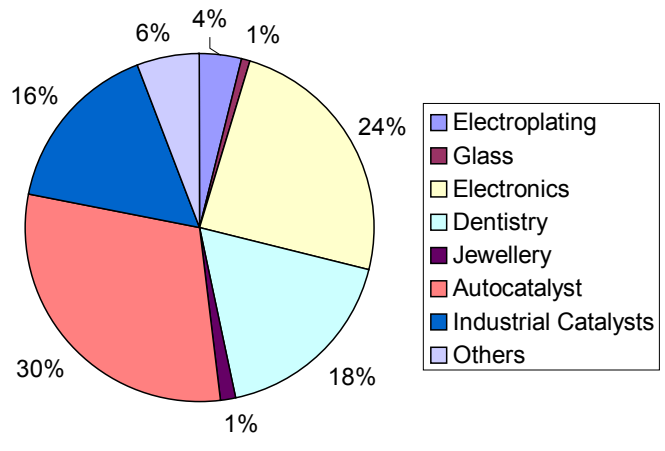

Figure 7: PGM recycling and PGM losses by sectors in Germany for base year 2001 
Germany's national inventory of PGMs was estimated in the region of 240 tonnes. This comprised $50 \%$ platinum, $45 \%$ palladium with the balance rhodium (Fig. 8 ).
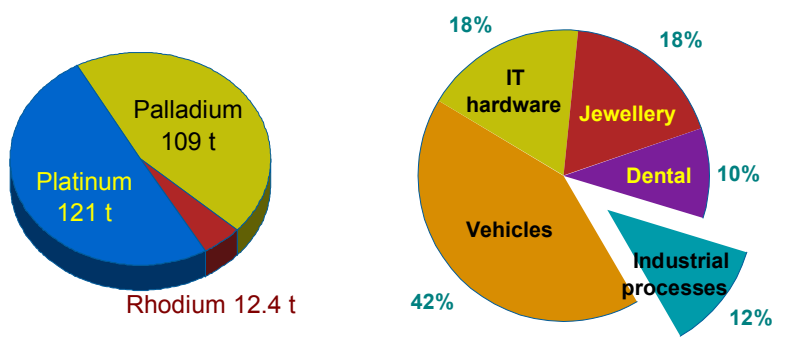

Figure 8: Germany's PGM inventory by metals and by sector (for base year 2001)

- The majority $(88 \%)$ of the national inventory is contained in consumer durable products held by private individuals. End-of-life PGM recycling from these sources is conducted through "indirect cycles" (see next chapter).

- $\quad 42 \%$ of the country's inventory is contained in autocatalysts fitted to vehicles in service.

Electronic hardware and jewellery each accounted for approximately $18 \%$ of inventory with PGMs contained in dental prosthetics representing a further $10 \%$.

- Only $12 \%$ of the national inventory resides in industrial processes. In the main this comprises PGMs contained in industrial catalysts and in equipment used to manufacture high purity glass. PGMs recovered from industrial processes are recycled through "direct cycles".

Looking at the very high share of consumer products, both in PGM net demand and inventory, it can be questioned if PGMs really are "industrial metals" as it is often postulated. And yet end-of-life consumer goods generate only $1 / 3$ of all recycled PGMs. The reasons are twofold: Certainly the long lifecycles of consumer products like automotive catalysts or electronics have an impact, but on top of this, fundamental differences can be observed in the recycling structures.

\section{LIFECYCLE STRUCTURES}

The report identifies two distinctly different forms of lifecycle structures, "direct cycles" and "indirect cycles". These are commonly referred to as closed (direct) and open loop (indirect) systems.

\subsection{Closed loops - key characteristic: recycling from industrial processes}

Closed loops (Fig. 9) prevail in industrial processes where PGMs are used to enable the manufacture of products or intermediates which typically contain no PGMs. Typical examples are PGM process catalysts (e.g. oil refining catalysts) or PGM-equipment used in the glass industry.

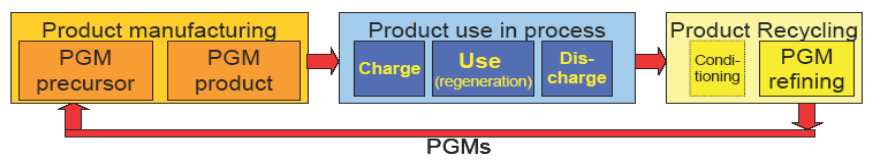

Figure 9: Closed (direct) loop recycling typically for industrial PGM-applications
- The PGMs invariably survive the process in which they are used, their recovery in most cases is an economic imperative. Their physical location is confined to the immediate vicinity of the user's plant. The user retains ownership of the PGMs and the system boundaries are restricted and well defined.

- In such processes the technical performance of the PGM products used (e.g. catalysts) is critical. As a result, close relationships exist between providers of the PGM products, its users and PGM refiners. Other parties are rarely involved.

- Typically, the provider of the PGM product operates refining facilities himself, or specialised refiners are involved, through which PGMs contained in spent products can be recycled into new PGM products.

- Handling of the PGM product along the entire lifecycle is usually done in a professional way, material flows are rather transparent.

- As a result, closed loop systems are inherently efficient and more than $90 \%$ of the PGMs used in industrial processes is typically recovered and recycled.

\subsection{Open loops - key characteristic: recycling from consumer durables}

Open loop systems (Fig. 10) are prevalent in the recycling of PGMs from end-of-life consumer durable products i.e. vehicles (autocatalysts), electronic hardware (components) and dental prosthetics.

- Consumer durables, in the main, are held by members of the general public. By the time such products reach the end of their useful lives (e.g. catalyst equipped cars) ownership may have changed hands several times and no connection remains between the final owner and its manufacturer.

- $\quad$ Little or no direct financial benefit exists to encourage final owners to ensure recycling of end-of-life products. Environmental concern and the need to find an outlet are the key drivers.

- Once consumer products enter the recycling system there are frequently a number of parties involved in the chain before PGM bearing materials reach the stage of final refining. These include collectors, dismantlers, traders and pre-treatment facilities.

- Recovery methods and awareness of PGM values is often limited. This results in inadequate removal and segregation of PGM bearing materials and irretrievable losses e.g. to shredders.

- The involvement of "informal" participants in the early stages of the recycling chain is significant. In such operations, working practices and regulatory compliance are poor. Especially the autocatalyst recycling sector has even partly attracted considerable criminal energy over the years.

- Significant numbers of end-of-life vehicles and electronic hardware (e.g. computers and mobile telephones) in Germany are exported for use in other less developed countries. As a result, the PGMs contained in such products escape recycling in Germany, and in many cases, will be lost for ever due to poor recycling infrastructures and environmental awareness in the importing countries.

- In end-of-life electronic hardware, PGM values are often extremely low and their recovery and recycling may not be economically viable.

- Open loop systems are highly complex structures containing multiple variables and numerous opportunities for the failure $\beta$ f PGM recovery Cpnsequently, 
open loops are inherently inefficient and recycling falls a long way short of its potential.

Recycling of old jewellery items is also conducted through open loop systems. Due to its high and very obvious value, levels of recovery are high. However, with an indeterminate lifecycle, jewellery is uniquely different and falls largely beyond the scope of this study.

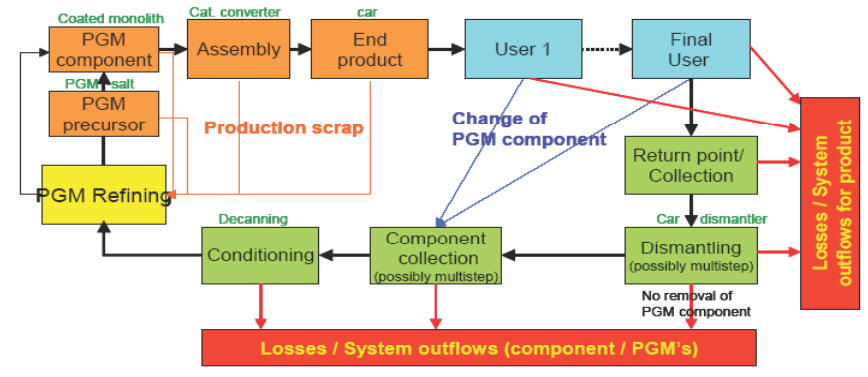

\begin{abstract}
Manufacturing $\square$ Use Recycling Logistics physical Recycling/Refining
Figure 10: Open (indirect) loop recycling for consumer
\end{abstract} products (example: autocat recycling)

\section{IMPROVING PGM RECYCLING}

Although it may be possible to further optimise PGM recycling within Germany's already efficient closed loop systems, the incremental benefits are likely to be relatively modest. The real challenge lies in finding ways to improve the performance of open loop systems, principally in respect of end-of-life vehicles and to a lesser extent, electronic hardware. In order to define the potential benefits the research partners have evaluated the impact of different scenarios through to 2020 .

\subsection{Autocatalyst recycling}

Even assuming continued open loop recycling and no improvements in recycling rates, PGMs recovered from used autocatalysts will treble by 2020 . This will be a natural function of an increasing proportion of vehicles scrapped each year that will be autocatalyst equipped, and the rising profile of PGM consumption in respect of newly registered vehicles.

However, with recycling rates remaining low and the available volume of PGMs rising, the quantity escaping the net will increase steeply and become irretrievably lost. By 2020 it is estimated that annual losses from the autocatalyst lifecycle could top 10 tonnes of PGMs. By contrast, a progressive conversion of existing open loop recycling systems into more efficient closed loops would drive up recycling rates. We estimate that closed loop recycling would more than double the recovery of PGMs from used autocatalysts by 2020 and slash losses.

End of Life Vehicle (ELV) recycling legislation has been adopted in Germany and the EU, which should be supportive of such a conversion taking place. This legislation assigns responsibility for recycling to the original manufacturer or importer of the vehicle. As a consequence, vehicle manufacturers are establishing reception and dismantling centres where "own marque" ELVs may be returned. Although this is a helpful development, we conclude that such legislation will need to be supplemented by other initiatives if PGM recycling from used autocatalysts is to reach its full potential. These include:

Increasing the awareness of PGM value and the benefits of recycling.
- Improving cooperation between participants in the recycling chain with a view to enhancing transparency and rationalising the system.

- The optimisation of dismantling and recovery procedures together with improved decanning techniques.

- Greater attention to improving logistics in order to optimise material flow.

- Action by competent authorities to certify and monitor recycling participants, eliminate informal sector participation and to regulate and control ELV exports.

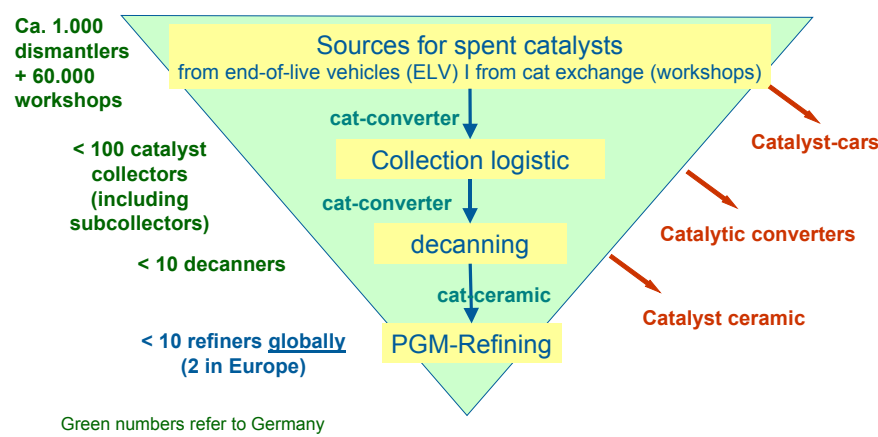

Figure 11: Recycling chain for autocatalysts with numbers of participants in Germany

\subsection{Recycling of electronic hardware}

In many respects the issues relating to end-of-life electronic goods are similar to those described for used autocatalysts. However, there are key differences which relate both to the low and declining levels of PGMs contained (in other words, grade) and the absolute decline in PGM usage (specifically of palladium) over recent years.

The two most important application areas for PGMs in electronics are hard disk drives (HDDs) and multi layer ceramic capacitors (MLCCs).

In HDDs, tiny amounts of platinum and more recently ruthenium are applied to the disks (creating high density memory layers) and to disk read heads. The disks are typically made of aluminium. At end-of-life, the value of the aluminium outweighs that of the platinum and so disks are channelled - also driven by established separation techniques - to aluminium smelters where the platinum is lost.

Palladium is an ingredient of MLCCs that are used in a variety of applications including mobile phones and computer peripherals. Since 2001, when the price of palladium reached $\$ 1,000$ per ounce, there has been a substantial shift away from palladium and to nickel based MLCCs. Consequently, the palladium contained in end-of-life electronic goods will decline sharply in future years. At the same time, ongoing miniaturisation and economy of use raise questions over the future viability of recycling such materials for their palladium value.

- Electronic goods contain many other metals which are of value and/or which can negatively impact health and the environment, if landfilled or treated in environmentally unsound processes. Among those are the precious metals gold, silver and ruthenium, special metals like indium, selenium, bismuth, antimony, cobalt, mercury, beryllium, as well as nonferrous metals copper, lead, tin, nickel and aluminium. Since most of these are concentrated in the circuit boards, the effective separation of the boards and their efficient treatment is of key significance. 
Modern integrated metals smelters and refineries have the capability to recover in sophisticated metallurgical flowsheets a wide range of precious, special and non-ferrous metals, while minimising waste and emissions into offgas or effluents. A further optimisation can be achieved by a more holistic approach in the recycling chain for electronic goods. Especially the interface between dismantling/preprocesing, often conducted through shredding and sorting, and subsequent metallurgical treatment has considerable optimisation potential. Target is to avoid dissemination of precious and special metals into the iron, aluminium or plastic/dust fraction, from where they usually get lost. In this context, mechanical preprocessing of circuit boards - due to their high complexity and interlinkage of metals and materials - has disadvantages to pyrometallurgical treatment in state-of-the-art integrated smelters.[7]

Although the available market may be shrinking in terms of PGMs, the recycling of redundant electronic goods is a high profile subject. Germany and the EU have adopted legislation which is similar to its ELV laws. Whilst this will be supportive of creating more efficient recycling systems, such legislation is not a solution in itself. The issues we have highlighted for autocatalyst recycling are equally valid if recycling from electronic goods is also to be optimised.

\section{ENVIRONMENTAL BENEFITS}

The extraction of PGMs from recycled materials results in significantly lower emissions than from equivalent amounts of PGMs generated by mining.

In recycling, basis the total amounts of PGM resulting from recycling and mine production, emission levels of carbon dioxide (equivalent) were calculated to be only $7 \%$ of those evolved during mine production. Sulphur dioxide emissions were assessed as negligible.

- In 2001 Germany's demand for newly mined PGMs equated to emissions in mine production of 300,000 tonnes of carbon dioxide and 20,000 tonnes of sulphur dioxide (both equivalents).

- Germany consumed only 5\% of global PGM mine production in 2001. 300,000 tonnes of carbon dioxide is equivalent to that emitted in production of 168,000 tonnes of steel.

Optimising PGM recycling offers clear environmental benefits. The potential conversion of open loop recycling systems to closed loops would serve to increase the supply of secondary PGMs and reduce dependence on mine production. Were this to be achieved, the increased supply of secondary PGMs would represent reduced emissions in mine production of 90,000 tonnes of carbon dioxide and 7,000 tonnes of sulphur dioxide by 2020 .

\section{CONCLUSION}

The platinum group metals are an indispensable part of our $21^{\text {st }}$ century lifestyle. The use of platinum in high quality, high fashion jewellery is long established and the use of palladium, its sister element, is increasingly evident in white gold and high purity palladium jewellery. However, whilst jewellery represents the visible face of the PGMs, it is behind the scenes and in more subtle ways that these rare and valuable metals make a real difference to every day lives.

Currently, about $50 \%$ of the world's newly mined PGMs are consumed in the production of autocatalysts, making use of their unique catalytic properties. Other important applications where the catalytic properties of PGMs play an essential role include the production of nitric acid, used primarily in nitrogen based fertilisers for food production, the catalytic reforming of naphtha into high octane vehicle fuels, the production of silicone compounds used as sealants and adhesives and in the synthesis of pharmaceutical compounds and speciality chemicals. Beyond catalysis the PGMs also play a central role in electronic components, including hard disk drives and ceramic capacitors, the manufacturing of fibreglass and liquid crystal displays and as important constituents of dental alloys.

PGMs are scarce, non-renewable natural resources. They are extremely durable and invariably survive both the industrial processes they are used in as well as the life cycle of the consumer products they are contained within. Because of their value and durability the PGMs are eminently recyclable. Because of their scarcity it is essential they are efficiently recovered from industrial processes and redundant products and recycled into new PGM products. A new publication from Yale University questioned, whether for copper, zinc and platinum the natural resources will remain sufficient in the long-term, if growth rates remain on the present high level and if recycling cannot be improved significantly. [8]

The research conducted by Umicore and Öko-Institute has examined PGM-lifecycles in considerable depth. Although the published report is a case study of the situation in Germany, it also serves as an invaluable reference for the PGM industry worldwide. The results of its analysis and its discussion of the issues will find resonance in many other countries and in numerous industries. In particular, its insights into the whole subject of PGM recycling shed new light on this highly complex area and will be of key importance to all market participants from mining companies and industrial users to refiners, fabricators, banks and traders.

\section{REFERENCES}

[1] Hagelüken, C., Buchert, M., Stahl, H., 2005, Stoffströme der Platingruppenmetalle, GDMB-Medienverlag, Clausthal-Zellerfeld.

[2] GFMS, Umicore, Öko-Institut, 2005, Materials flow of platinum group metals, GFMS, London.

[3] Hagelüken, C., Buchert, M., Stahl, H., 2003, Substantial outflows of PGMs identified, Erzmetall, 56/9: 529-540.

[4] Johnson Matthey, 2005, Platinum 2005, London.

[5] GFMS, 2005, Platinum \& Palladium Survey 2005, London.

[6] Hagelüken, C., 2006, Markets for the catalyst metals platinum, palladium and rhodium, Metall 60/1-2, 810821.

[7] Hagelüken, C., 2005, Recycling of electronic scrap at Umicore's integrated metals smelter and refinery, Proceedings EMC 2005, Vol. 1, 307-323.

[8] Gordon, R., Bertram, M., Graedel, T., 2006, Metal stocks and sustainability, PNAS 103/5, 1209-1214.

\section{CONTACT}

Christian Hagelüken

Umicore AG \& Co KG, Precious Metals Refining, Rodenbacher Chaussee 4, D-63457 Hanau, Germany, christian.hagelueken@eu.umicore.com 